\title{
Nieniszcząca ocena grubości warstw natryskiwanych cieplnie metodą topometrii laserowej
}

\section{Non-destructive evaluation of thermal sprayed layer thickness by laser topometry}

\section{Streszczenie}

W artykule przedstawiono wyniki badań dotyczące nieniszczącej oceny grubości powłok otrzymywanych metodą natryskiwania plazmowego z użyciem laserowej topometrii 3D. Do pomiarów wykorzystano system ATOS firmy GOM, który pozwala na wykonywanie szybkich pomiarów obiektów przy wysokiej rozdzielczości. Analizie poddano ceramiczną warstwę izolującą powłoki TBC otrzymaną na łopatce turbiny gazowej. Charakterystyki grubości warstwy ceramicznej dokonano w losowo wybranych punktach oraz na przekrojach poprzecznych łopatki. Uzyskane wyniki przedstawiono w postaci wartości liczbowych odpowiadających konkretnym miejscom na łopatce, w postaci kolorowych map odzwierciedlających rozkład grubości warstwy ceramicznej na dowolnie wybranym przekroju oraz w postaci map 3D. Zlokalizowano miejsca na powierzchni łopatki, które charakteryzują się niejednorodnym rozkładem grubości mierzonej warstwy.

\section{Abstract}

The paper presents results of research on non-destructive evaluation of coating thickness obtained by plasma spraying using a 3D laser topometry. For the measurements was used GOM's ATOS system, which is used to perform fast measurements of objects with high resolution. The analysis of the ceramic insulating layer TBC coatings was obtained on a gas turbine blade. The characteristics of the ceramic layer thickness were made at randomly selected points and cross sections of the blade. The results presented in the form of numerical values corresponding to specific sites on the blades, in the form of colorful maps reflecting the distribution of the ceramic layer thickness for any given cross-section and as a 3D map. The parts of layer characterized by a heterogeneous distribution of the thickness were located on the surface of blade.

\section{Wstęp}

Natrysk plazmowy umożliwia natryskiwanie szerokiej gamy materiałów proszkowych, a proces technologiczny może być prowadzony przy ciśnieniu atmosferycznym lub pod obniżonym ciśnieniem w specjalnych komorach. Ze względu na wymagania stawiane warstwom natryskiwanym proces ich wytwarzania realizowany jest z wykorzystaniem manipulatorów, systemów obrotu oraz chłodzenia i najczęściej jest to proces zautomatyzowany, gdzie robot operuje pistoletem

Dr inż. Grzegorz Moskal, mgr inż. Bartosz Witala - Politechnika Śląska, Katowice, mgr. inż. Radosław Swadźba - Instytut Metalurgii Żelaza. plazmowym $[1 \div 6]$. Mimo to zasadniczym problemem jest uzyskanie efektu w postaci równomiernej pod względem grubości powłoki na całej pokrywanej powierzchni np. łopatki lub komory spalania (rys. 1). W zastosowaniach przemysłowych zasadniczym problemem jest również umiejętność oceny grubości powłoki na gotowych elementach bez konieczności ich niszczenia, nawet jeżeli byłyby to próby losowe. Sytuację utrudnia również fakt, iż w wielu przypadkach mamy do czynienia z powłokami kilkuwarstwowymi, jak np. powłokowe bariery cieplne zbudowane z zewnętrznej warstwy ceramicznej, warstwy tlenków TGO oraz warstwy podkładowej (rys. 2). Ponadto każdy z klientów żąda powłok o innej grubości. Proponowana w niniejszym artykule metoda oceny umożliwi szybką i dokładną ocenę grubości powłok lub wybranych warstw w dowolnym punkcie lub przekroju analizowanego elementu. 

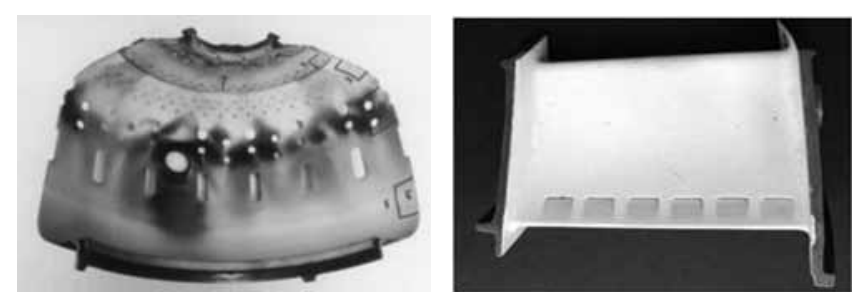

Rys. 1. Przykłady zastosowania powłok TBC na fragmencie komory spalania i łopatce kierującej turbiny gazowej [7]

Fig. 1. Examples of TBC coatings in the piece of blast chamber and stator blade of gas turbine [7]

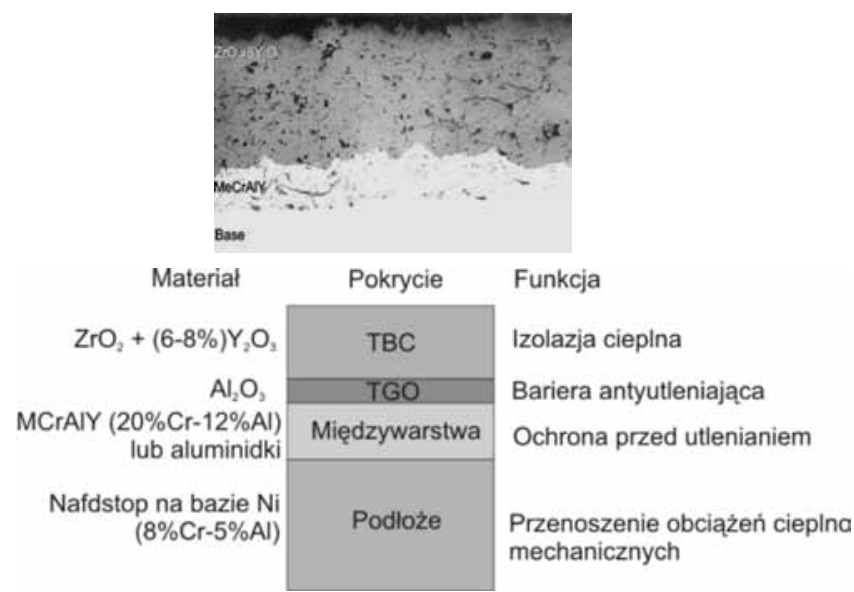

Rys. 2. Mikrostruktura powłoki TBC natryskiwanej plazmowo oraz rola jej poszczególnych elementów [7]

Fig. 2. Microstructure of TBC coating plasma transferred arc spraying and the aim of its layers

W literaturze spotkać można wiele danych dotyczących metodyki badań nieniszczących powłok, w tym natryskiwanych cieplnie. Dotyczą one głównie powłokowych barier cieplnych i zalicza się do nich m.in. metody oparte na optyce laserowej. Jedną z metod optyki laserowej, mającą szczególne znaczenie przy badaniu powłok TBC otrzymywanych metodą EB-PVD, jest spektroskopia luminescencyjna

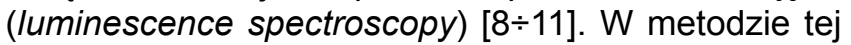
laser pobudza jony $\mathrm{Cr}^{3+}$, znajdujące się $\mathrm{w}$ warstwie TGO, których koncentracja współzależy od poziomu naprężeń występujących w TGO. Kolejną z metod jest technika EOS (elastic optical scattering), służąca do wykrywania delaminacji oraz obszarów przedodpryskowych [12, 13]. W metodzie tej, opracowanej w ANL (Argonne National Laboratory), spolaryzowane światło lasera o niskiej mocy (poniżej $35 \mathrm{~mW}$ ) wnika w głąb warstwy TGO, gdzie ulega odbiciu na granicy faz. Bardzo ważną, wymaganą od powłok TBC cechą jest ich jednakowa grubość na całej powierzchni pokrytego przedmiotu. Aktualnie używana metoda badań grubości powłok TBC, będącą jednocześnie ciągle w rozwoju, jest metoda tomografii optycznie spójnej (OCT - optical coherence tomography) [14]. W technice tej, która umożliwia bezpośrednie mierzenie grubości warstw, laser małej mocy połączony jest światłowodem z interferometrem, co pozwala na uzyskiwanie obrazu przekroju poprzecznego.

\section{Procedura eksperymentu}

Badaniu poddano łopatkę pokrytą międzywarstwą typu NiCrAlY oraz zewnętrzną warstwą ceramiczną na bazie cyrkonianu gadolinu. W celu wykonania międzywarstwy zastosowano natrysk plazmowy w próżni, natomiast dla warstwy ceramicznej wykorzystano natrysk plazmowy w powietrzu. W obu przypadkach zastosowano standardowe dla danego materiału parametry procesu.

Do realizacji badań wykorzystano przemysłowy system ATOS (Advanced Topometric Sensor). System ten umożliwia wykonywanie szybkich pomiarów obiektów przy wysokiej rozdzielczości w skali 3D. System ten działa na zasadzie triangulacji: optyczny czujnik narzuca na powierzchnię badanego obiektu wzór w postaci prążków, który następnie rejestrowany jest przez dwie kamery umieszczone względem siebie równolegle. W celu otrzymania kompletnego obrazu cyfrowego badanego obiektu należy wykonywać kilka pomiarów pod różnym kątem głowicy pomiarowej w stosunku do badanego obiektu. Dzięki zastosowaniu punktów referencyjnych, mających postać czarno-białych znaczników umieszczanych na powierzchni badanego (skanowanego) obiektu, możliwe jest automatyczne połączenie pojedynczych pomiarów w całość. Uzyskany w ten sposób obraz cyfrowy można zaprezentować $w$ jednej $z$ trzech postaci: chmury punktów, siatki trójkątów (format STL) i przekrojów.

W celu uzyskania obrazu 3D obiektów o skomplikowanym kształcie należy proces pomiarowy podzielić na kilka oddzielnych części. Taka metoda stosowana może być szczególnie wówczas, gdy nie jest możliwe skanowanie górnej i dolnej części obiektu w tym samym procesie pomiarowym. Po przeprowadzeniu kilku procesów pomiarowych obejmujących różne obszary obiektu można je połączyć w całość za pomocą wspólnych punktów referencyjnych.

\section{Wyniki badań}

Punktem wyjścia dla prowadzonej oceny grubości warstw natryskiwanych cieplnie jest obraz łopatki przed procesem natrysku plazmowego $w$ postaci chmury punktów. Widok takiej łopatki przedstawiono na rysunku 3. Pokazano na nim obraz koryta oraz grzbietu łopatki, a także szczegóły przedstawiające krawędź natarcia oraz krawędź spływu (rys. 3a). Szczegółowe obrazy powierzchni łopatki w obszarze grzbietu oraz krawędzi spływu wykazały, że charakteryzuje się ona dużą gładkością (rys. 3b). Analogiczny obraz uzyskano dla powłok TBC z zewnętrzną warstwą ceramiczną (rys. 4a i b).

$\mathrm{Na}$ pierwszy rzut oka widoczna jest różnica $w$ topografii powierzchni łopatki z powłoką TBC, co wynika z morfologii samej warstwy ceramicznej uzyskanej metodą natryskiwania plazmowego. Charakteryzuje się ona chropowatą powierzchnią będącą efektem 
a)

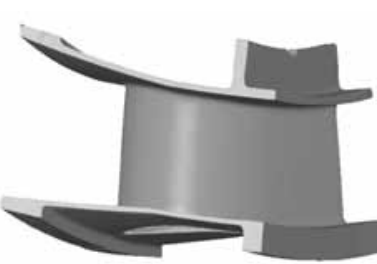

grzbiet łopatki

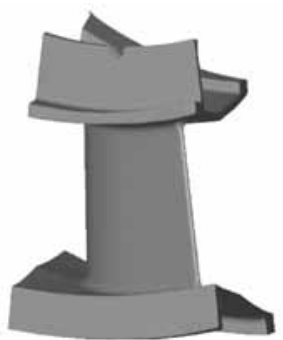

krawędź spływu łopatki

b)

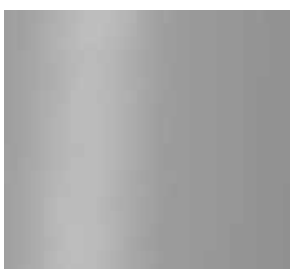

Szczegół powierzchni z grzbietu łopatki

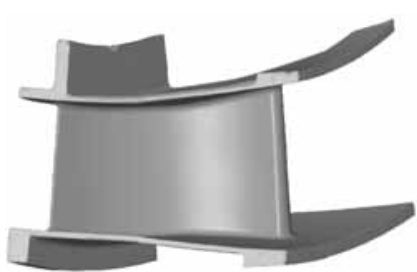

koryto łopatki

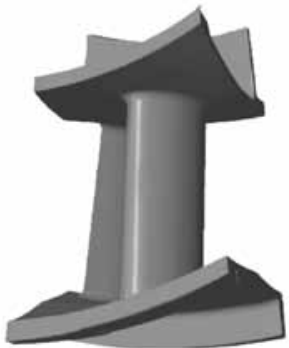

krawędź natarcia łopatki

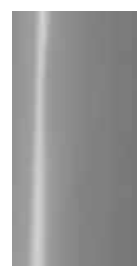

Szczegół powierzchni z krawędzi natarcia łopatki

Rys. 3. Cyfrowy obraz łopatki przed natryskiem plazmowym powłoki TBC $w$ postaci chmury punktów (szczegóły z rys. 5)

Fig. 3. Digital image of blade before plasma transferred arc spraying of TCB coating as the points (details form fig. 5)

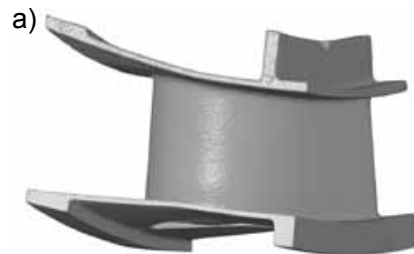

grzbiet łopatki

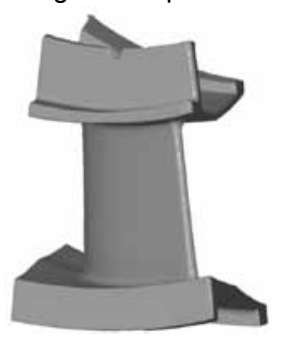

b)
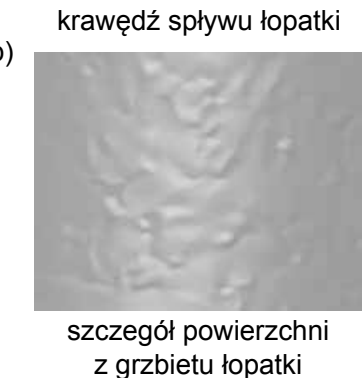

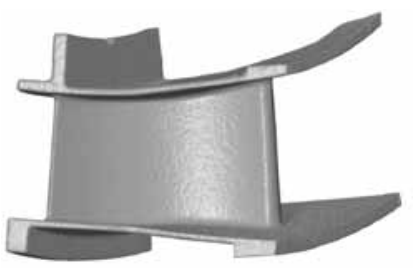

koryto łopatki

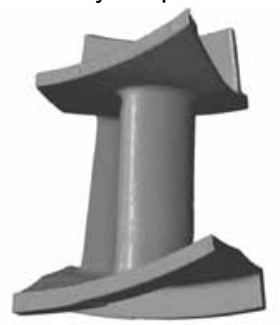

krawędź natarcia łopatki

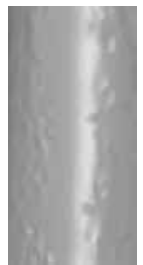

szczegół powierzchni z krawędzi natarcia łopatki

Rys. 4. Cyfrowy obraz łopatki przed natryskiem plazmowym powłoki TBC w postaci chmury punktów

Fig. 4. Digital image of blade after plasma transferred arc spraying of TCB coating as the points
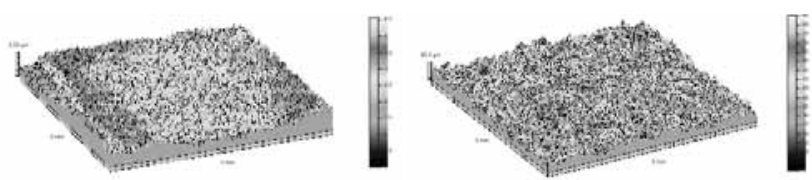

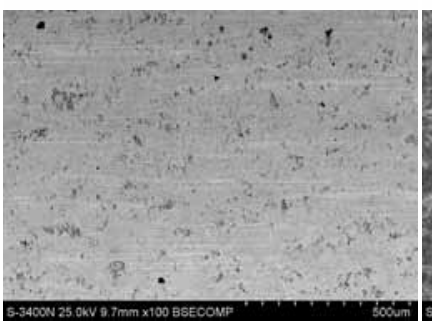

Powierzchnia łopatki

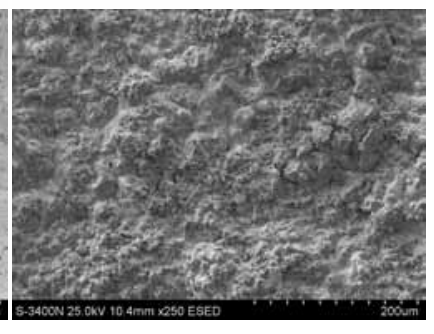

Powierzchnia łopatki $z$ warstwą TBC

Rys. 5. Wyniki badań topografii powierzchni łopatki bez i z powłoką TBC oraz mikrostruktura powierzchni

Fig. 5. Results of blade surface analysis with and without TBC coating and the microstructures

rozpłaszczania się kropel ciekłych ceramiki na pokrywanej powierzchni w postaci płaskich dysków i ich krzepnięcia. Na rysunku 5 przedstawiono wyniki badań topografii powierzchni profilometrem laserowym powierzchni łopatki bez powłoki i z powłoką natryskiwaną cieplnie.

Różnica w cyfrowych obrazach łopatki bez powłoki i z powłoką TBC, przedstawionych na rysunkach 3 i 4, stała się podstawą do oceny grubości warstwy ceramicznej. Możliwości programowe systemu pozwalają na charakterystykę tego parametru w dowolnym punkcie lub przekroju analizowanego elementu. Jedynym warunkiem jest poprawne „zeskanowanie” elementu. Przykładowe wyniki takiej oceny w postaci punktów oraz przekrojów przedstawiono na rysunku 6. Wykazują one, że grubość warstwy ceramicznej

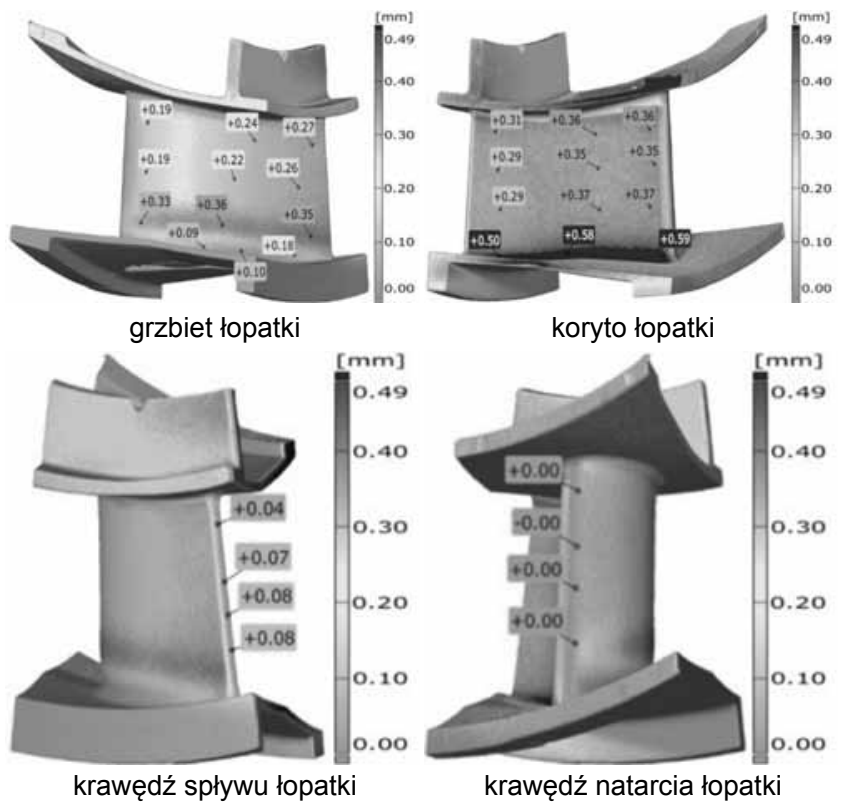

Rys. 6. Obraz łopatki wraz z powłoką TBC i mapa grubości warstwy ceramicznej

Fig. 6. The blade with TBC coating and the map of ceramic layer thickness 
jest niejednorodna i waha się od 90 do $590 \mu \mathrm{m}$ w zależności od miejsca. Ponadto na krawędzi spływu i natarcia praktycznie warstwa nie została osadzona. Najgrubszą warstwę ceramiczną obserwowano w obszarze przejścia pióra łopatki w strefę zamka. Ponadto zdecydowanie większą grubość warstwy uzyskano w obszarze koryta łopatki w porównaniu z jej grzbietem.

Uzyskane informacje wskazują, że materiał podłoża w obszarze krawędzi natarcia i spływu łopatki nie jest praktycznie chroniony i jako pierwszy zostanie poddany oddziaływaniu wysokiej temperatury i agresywnych gazów roboczych (rys. 7). Tam też należy spodziewać się pierwszych objawów zniszczenia. Ponadto w miejscu o zbyt grubej warstwie ceramicznej należy spodziewać się defektów w postaci pękania i odpadania warstwy.

Na podstawie informacji zdobytych metodą topometrii laserowej można więc dokonać korekcji podstawowych parametrów procesu natryskiwania cieplnego i skorygować stwierdzone odchyłki od założeń projektowych.
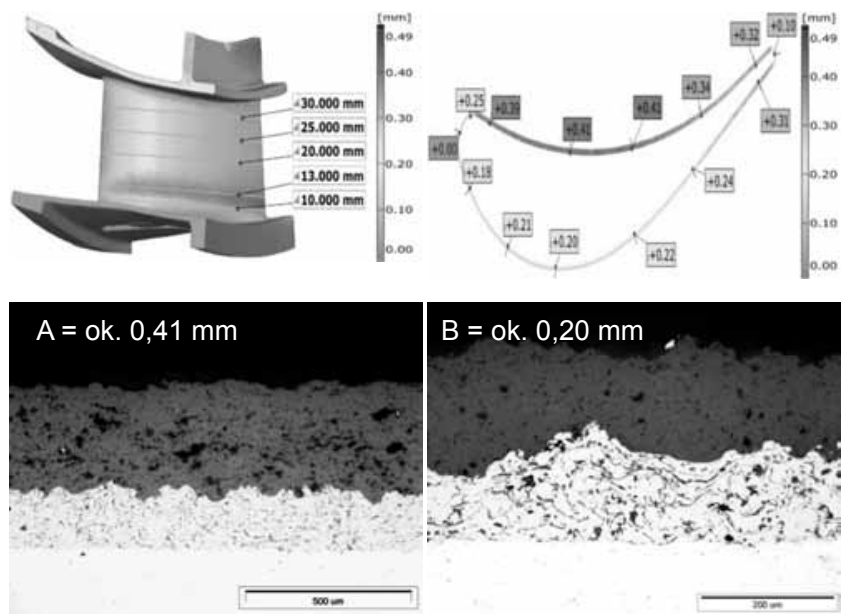

Rys. 7. Rozkład grubości warstwy ceramicznej na przekroju i odpowiadające mu obrazy mikrostruktury

Fig. 7. Thickness distribution of ceramic layer in the cross-section and corresponding to it microstructures

\section{Wnioski}

Zastosowanie nieniszczącej metody oceny grubości powłok natryskiwanych cieplnie, opartej na topometrii laserowej, umożliwia dokładną i szybką ocenę grubości warstw natryskiwanych cieplnie na rzeczywistych elementach, nawet o dużych wymiarach, bez konieczności ich cięcia.

Metoda ta pozwala na wirtualne cięcie badanego elementu i analizę uzyskanych wyników w dowolnym przekroju lub punkcie.
Określenie stopnia niejednorodności grubości natryskiwanej warstwy może być źródłem informacji dotyczącym potencjalnych miejsc inicjacji i propagacji uszkodzeń.

Wyniki uzyskane na podstawie takich pomiarów, a zwłaszcza na temat niejednorodnej grubości warstwy, stanowią źródło informacji dla technologów dotyczące parametrów procesu natryskiwania cieplnego.

\section{Literatura}

[1] Bevan D.J.M., Summerville E.: In Handbook on the Physics and Chemistry of Rare Earths: Non-Metallic Compounds I, ed. Gschneider K. A. and Eyring, L. R., North-Holland Physics Publishing, New York, USA, 1979, s. 412.

[2] Clarke D.R., Phillpot S.R.: Thermal barierr coatins materials, Materials Today, June 2005, s. 22-29.

[3] Yu Z., Dharmasena K.P., Hass D.D., Wadley H.N.G.: Vapor deposition of platinum alloyed nickel aluminide coatings, Surf. Coat. Technol., 201, 2006, s. 2326-2334.

[4] Schulz U. et al.: Some recent trends in research and technology of advanced thermal barrier coatings, Aerospace Science and technology 7, 2003, s. 73-80.

[5] Levi C.G.: Emerging materials and processes for thermal barrier system, Current Opinion in Solid State and Materials Science 8, 2004, s. 77-91.

[6] Wigren J. Pejryd L.: Thermal barrier coatings-why, how, where and where to. In Proceedings of the 15th International Thermal Spray Conference: Thermal Spray Meeting the Challenges of the 21st Century (Nice, France, May 1998), ed. Christian Coddet. ASM International, Materials Park, OH, USA, 1998, s. 1531-1542.

[7] Moskal G., Swadźba L. - opracowania własne.

[8] Steckenrider J.S., Ellingson W.A.: Application of Laser Scattering to the Detection of Surface and Subsurface Defects in Si3N4 Component, Ceram. Eng. Sci. Proc. 15, 1994. s. $382-89$

[9] Clarke D.R., Christensen J.R., Tolpygo V.: The Evolution of Oxidation Stresses in Zirconia Thermal Barrier Coated Superalloy Leading to Spalling Failure Surf. Coat. Technol., 94/95, 1997, s. 89-93.

[10] Peng X., Clarke D.R.: Piezospectroscopic Analysis of Interface Debonding in Thermal Barrier Coatings J. Am. Ceram. Soc. 83,2000 , s. $1165-70$

[11] Topygo V.K., Clarke D.R. I Murphy K.S.: Evaluation of Interface Degradation during Cyclic Oxidation of EB-PVD Thermal Barrier Coatings and Correlation with TGO Luminescenc, Surf. Coat. Technol., 188-189, 2004, s. 62-70.

[12] Stover J.C.: Optical Scattering and Analysis, SPIE Optical Engineering Press, Bellingham, Washington, s. 111-133 (1995).

[13] Ellingson W.A., Todd J.A., Sun J.: Optical Method and Apparatus for Detection of Defects and Microstructural Changes in Ceramics and Ceramic Coatings, U.S. Patent 6,285,449 (2001).

[14] Bouma B.E., Tearney G.J.: Handbook of Optical Coherence Tomography, Marcel Dekker, New York, 2002.

Badania realizowane w ramach Projektu Nr POIG. 01.01.02-00-015/09 w Programie Operacyjnym Innowacyjna Gospodarka (POIG). Projekt współfinansowany przez Unię Europejską ze środków Europejskiego Funduszu Rozwoju Regionalnego. 